\title{
Editorial: Frontiers in Seafloor Geodesy
}

\author{
Ryota Hino ${ }^{1 *}$, Keiichi Tadokoro ${ }^{2}$ and Laura Wallace ${ }^{3,4}$ \\ ${ }^{1}$ Graduate School of Science, Tohoku University, Sendai, Japan, ${ }^{2}$ Earthquake and Volcano Research Center, Graduate School of \\ Environmental Studies, Nagoya University, Nagoya, Japan, ${ }^{3}$ Institute of Geophysics, University of Texas at Austin, Austin, TX, \\ United States, ${ }^{4}$ GNS Science, Lower Hutt, New Zealand
}

Keywords: GNSS-acoustic, seafloor pressure, ocean models, differential bathymetry, tilt and strain observations

\section{Editorial on Research Topic}

\section{Frontiers in Seafloor Geodesy}

Seafloor geodetic methods, including techniques such as GNSS-Acoustic surveys (and other forms of acoustic ranging), and monitoring of changes in seafloor pressure, and downhole pressure allow for measuring crustal deformation over Earth's vast areas that are covered by water and therefore inaccessible to traditional geodetic techniques developed for onshore use. Since the 1980s when the concept of seafloor displacement monitoring with precise acoustic ranging was proposed, significant efforts have been made to implement and improve seafloor geodetic measurements to reveal the motion and deformation of oceanic tectonic plates, earthquake processes at subduction zones and other plate boundaries, and the deformation of submarine volcanoes and spreading centers (Bürgmann and Chadwell, 2014). Although remarkable technological progress has been made to increase the precision and scales of observations with improving the reliability and cost-effectiveness of the instrumentation, there still remain a number of difficulties to overcome in seafloor geodetic observations. This Research Topic gathers field experiments and/or new techniques and perspectives obtained through a range of data acquisition efforts in order to leverage them to advance in seafloor geodetic research.

The GNSS-Acoustic technique obtains a precise location of seafloor transponder arrays (often

Edited and reviewed by: Carolina Lithgow-Bertelloni, UCLA Department of Earth, Planetary, and Space Sciences, United States

${ }^{*}$ Correspondence:

Ryota Hino hino@tohoku.ac.jp

Specialty section: This article was submitted to Solid Earth Geophysics, a section of the journal Frontiers in Earth Science

Received: 20 July 2021

Accepted: 27 July 2021

Published: 09 August 2021

Citation:

Hino $R$, Tadokoro $K$ and Wallace $L$ (2021) Editorial: Frontiers in Seafloor Geodesy.

Front. Earth Sci. 9:744217. doi: 10.3389/feart.2021.744217 deployed on benchmarks) by combining locations of an observation platform on the sea surface determined by GNSS observations and acoustic ranging between the transponders and the platform. Repeated measurements of the benchmark positions over years allow centimeter-level resolution of horizontal tectonic motions of the seafloor. Measurements of coseismic and postseismic deformation near the hypocenters of offshore earthquakes (e.g., Tadokoro et al., 2006), including those of the 2011 Tohoku Earthquake (Kido et al., 2011; Sato et al., 2011; Tomita et al., 2017), and $\sim \mathrm{cm} / \mathrm{yr}$ resolution of interseismic deformation field at the Peru-Chile Trench (Gagnon et al., 2005) and the offshore Nankai Trough (Yokota et al., 2016) are pronounced achievements of the seafloor observations of this kind. Chen et al. (this issue) reported crustal deformation related to rifting at the Okinawa trough, which is in the early stage of backarc opening. They utilize GNSS-A measurements acquired over 10 years, to reveal rifting rates at $\sim 43 \mathrm{~mm} / \mathrm{yr}$.

In the development of the GNSS-Acoustic technique, much effort has been made to increase the accuracies of underwater acoustic ranging. Watanabe et al. (this issue) describe a technique of jointly estimating benchmark locations and sound speed structure in the ocean. This technique is routinely used by the Japan Coast Guard in their GNSS-A surveys. In a similar vein, Honsho et al. (this issue) applied a novel cross correlation method to acoustic ranging to reduce uncertainties in two-way travel time measurements.

As measurement uncertainties decrease, displacement time series of GNSS-Acoustic surveys are expected to provide not only a long-term average rate of deformation, but also to reveal temporal fluctuations in deformation rate associated with episodic tectonic motions (Yokota and Ishikawa, 2020), such as Slow Slip Events (SSEs). However, reliability of transient deformation event detections is 
not solely dependent on the measurement accuracies, but also relies in an increased temporal frequency of repeated measurements, demanding technological developments to increase the efficiency of field measurements. Ishikawa et al. (this issue) review how onboard instrumentation and survey strategies have been improved by the Japanese Coast Guard and Nakamura et al. (this issue) evaluate optimum survey geometries, to improve of observational efficiencies. Utilizing unmanned craft equipped with navigation and acoustic ranging systems of equivalent quality to those on research ships, as reported by Sakic et al., Iinuma et al. and Tadokoro et al. (this issue) helps to decrease costs of each survey and thus increase the number of GNSS-Acoustic surveys that can be undertaken, potentially even moving towards continuous, real-time measurements (Tadokoro et al., this issue).

Recent success in monitoring spatio-temporal variation of interplate slip rates along subduction zones is a societally important motivation for geoscientists to build offshore geodetic monitoring networks at largely un-instrumented offshore subduction zones. Murakami et al. (this issue) demonstrate the need for GNSS-Acoustic observations to evaluate interplate coupling strength off the Hokkaido, Japan, where an interplate earthquakes with destructive tsunami is considered to be impending based on the paleotsunami geological research (Ioki and Tanioka, 2016).

Vertical displacement on the seafloor can be detected as a change in water pressure. As precise, low-power, and robust pressure sensors are now widely available, small Ocean Bottom Pressure Recorders (OBPRs) have been developed which can freefall from a ship (to settle on the seafloor) and recovered with acoustic release systems, following the designs of Ocean Bottom Seismographs (OBSs). Seafloor deformation associated with various tectonic phonemena have been recorded by 1-2 years deployment of OBPRs, such as the pre- co- and post-seismic deformations associated with the 2011 Tohoku Earthquake (e.g., Iinuma et al., 2012; Iinuma et al., 2016), Slow Slip Events (SSEs) on the subduction interfaces (Wallace et al., 2016; Sato et al., 2017), as well as inflation and deflation associated with submarine volcanic eruptions (e.g., Chadwick et al., 2012). Because pressure sensors also detect sea level changes due to tsunami, real-time seafloor pressure monitoring by submarine cabled systems has now been realized in several subduction zones to improve reliability of early tsunami warning immediately after large earthquakes (e.g., Aoi et al., 2020). The pressure records obtained by such seafloor networks are also expected to shed light on vertical tectonic motions on these offshore plate boundaries.

There are two major challenges for seafloor pressure measurements to enhance their ability to detect centimeterlevel tectonic motions: removal of long-term instrumental drift intrinsic to pressure sensors, and shorter-term pressure fluctuation caused by oceanographical phenomena. Drift rate of the pressure sensors commonly used for seafloor geodetic applications is order of $1 / 10^{4}$ per year of the pressure sensor full range (e.g., Polster et al., 2009), which is equivalent to several $\mathrm{cm}$ to tens of $\mathrm{cm}$ per year for pressure sensors intended for thousands of meters water depth. The drift rate is much larger than expected rates of vertical motions associated with secular tectonic motions, which are $\mathrm{mm}$ to $\mathrm{cm} / \mathrm{yr}$. Recent careful laboratory experiments clarify that the drift characteristics is complex, and the rate is dependent on the time history of applied pressure, making it difficult to estimate the drift rate through laboratory tests prior to deployment (Kajikawa and Kobata, 2019). Matsumoto and Araki (this issue) compare drift rates of pressure sensors deployed along the DONET cabled network at the offshore Nankai Trough, with those obtained by pressurization of the same sensors in the laboratory prior to the deployment, to exemplify the difficulty of this approach and to emphasize importance of in-situ sensor calibration. Wilcock et al. (this issue) show the viability of a new method of in situ calibration (the "A-0-A" method) during a 30 months deployment of this system on the MARS cable beneath Monterey Bay. Their results demonstrate the accuracy of seafloor pressure records corrected by the method is better than $1 / 10^{5}$ per year, providing a promising approach to measure secular vertical deformation at plate boundaries with OBPRs.

Short-term oceanographical fluctuations present another major challenge for resolving tectonic deformation with OBPRs. Removal of common mode fluctuations in ocean bottom pressure records from nearby stations (e.g., Ito et al., 2013; Hino et al., 2014) is a common way to address this issue, assuming that the oceanographical pressure variations have spatial similarities over a broader scale than tectonic deformation events. Another approach is to calculate the pressure variations based on ocean circulation models (e.g., Inazu et al., 2012). Dobashi and Inazu (this issue) assess the performance of different global ocean models to predict seafloor pressure at several subduction zones. Their work also demonstrates the importance of incorporating atmospheric pressure changes into the ocean models-they obtain a better agreement between the seafloor pressure data and model predictions. It is clear from this and other studies that integration of physical oceanography is key to improving use of seafloor pressure measurements to reveal tectonic deformation.

This research topic includes three papers providing interpretations of seafloor geodetic records in terms of physical oceanographic processes. Nagao et al. (this issue) discuss how meandering of Kuroshio current influences seafloor pressure recorded along the Nankai Trough based on DONET observations. Hasegawa et al. (this issue) analyzed seafloor pressure and sea surface records using a highresolution ocean assimilation model and discuss how sea water density anomalies may have significant effects on the seafloor pressure variability. Using the same ocean assimilation model, Yokota et al. (this issue) interpret underwater sound speed structure, estimated during GNSS-A data analyses, and conclude that the sound structure represents local scale heterogeneity which cannot be reproduced by the ocean model.

Measurements of pressure change in the formation beneath the seafloor via subseafloor observatories is promising approach to detect transient crustal deformation with a higher signal-tonoise ratio than other seafloor geodetic methods, including smaller-scale, possibly more frequent, tectonic events than those that can be detected by observations on the seafloor. This technique relies on formation pressure changes as a 
proxy for volumetric strain and have provided valuable data set regarding slow slip event (SSE) activity (e.g., Davis et al., 2015; Araki et al., 2017) at offshore subduction zones. Ariyoshi et al. (this issue) report an episodic changes in pore pressure observed at a borehole observatory connected to DONET, as a result of migrating SSEs occurring on the offshore Nankai Trough.

Tilt measurements have a long history as a tool for continuous monitoring of crustal deformation. Owing to the high sensitivity of tiltmeters in the frequency band specific to SSEs, a number of important characteristics of SSEs have been clarified by the tilt observation network covering onshore of SW Japan (e.g., Hirose et al., 2010). To fully realize offshore tilt measurements, extensive efforts have been made. Shiobara et al. (this issue) report the present status of development of a new ocean-bottom tiltmeter, using mass-position of a three-component broadband seismometer with observed data obtained by field trials.

Repeated multibeam bathymetric surveys can provide spatial variations in seafloor deformation over broad area, in contrast to other geodetic measurements that detect a motion at an observing point. Although large uncertainties in measured displacement place limits on the applications of this method, the results of differentiating bathymetric maps before and after the 2011 Tohoku Earthquake constrained the coseismic slip distribution near the Japan Trench owing to the extremely large displacement (tens of meters) by the earthquake (Fujiwara et al., 2011). Fujiwara (this issue) overviews the factors influencing uncertainties of shipboard bathymetry measurements, and suggest ways to enhance resolution as much as possible, and to assess the data quality.

Seafloor geodetic measurements aim to measure crustal deformation in response to tectonic processes, but long-term monitoring of other geophysical parameters is needed to understand the physical processes behind the observed crustal deformation. For example, several studies have shown that fluid migration and hydrological changes within the solid Earth may play significant roles in fault slip processes (Bhattacharya and Viesca, 2019; Warren-Smith et al., 2019). Electromagnetic field measurements are sensitive to the distribution of fluids, and long term-monitoring of this will help to constrain models for the role of fluid migration in the occurrence of tectonic deformation processes. Kasaya et al. (this issue) present a system to measure changes in resistivity and self-potential at the seafloor, applied in this case to a hydrothermal system.

\section{REFERENCES}

Aoi, S., Asano, Y., Kunugi, T., Kimura, T., Uehira, K., Takahashi, N., et al. (2020). MOWLAS: NIED Observation Network for Earthquake, Tsunami and Volcano. Earth Planets Space 72 (1), 126. doi:10.1186/s40623-020-01250-x

Araki, E., Saffer, D. M., Kopf, A. J., Wallace, L. M., Kimura, T., Machida, Y., et al. (2017). Recurring and Triggered Slow-Slip Events Near the Trench at the Nankai Trough Subduction Megathrust. Science 356, 1157-1160. doi:10.1126/ science.aan 3120

Bhattacharya, P., and Viesca, R. C. (2019). Fluid-induced Aseismic Fault Slip Outpaces Pore-Fluid Migration. Science 364, 464-468. doi:10.1126/science.aaw7354
Seafloor geodetic techniques are also being developed for shallow water environments. De Martino et al. (this issue) report on horizontal and vertical crustal deformation associated with volcanic activity at Campi Flegrei Caldera, Italy. They successfully detected deformation using 4 years of GNSS measurements on buoys attached to the seafloor in a shallow $(<100 \mathrm{~m})$ water environment. The team also employs a range of other measurements at each buoy (seafloor pressure, ocean bottom seismology) to enhance monitoring ability of this dangerous volcanic system.

Seafloor geodesy is a rapidly emerging field, and is continually revealing new insights into a range of offshore tectonic processes in plate boundary zones. As presented in this research topic, major efforts to improve observational technologies are underway to enhance our detection ability of subsea tectonic motions. In addition to hardware development, it is equally important to distinguish between tectonic seafloor motions and physical oceanographical and/or meteorological variations in seafloor geodetic observations. Acquisition of additional seafloor geodetic and oceanographic observations are necessary to improve our ability to detect offshore tectonic deformation, and collaborations between physical oceanographers and solid Earth scientists will lead to breakthroughs in developing novel methods enhance signal-to-noise ratios of the offshore geodetic observations. We expect that such efforts will also benefit ocean environmental monitoring.

\section{AUTHOR CONTRIBUTIONS}

$\mathrm{RH}$ wrote this article, while KT and LW provided comments for improvement on this brief overview.

\section{FUNDING}

This work was supported partly by JSPS KAKENHI JP19H05596.

\section{ACKNOWLEDGMENTS}

We thank Valerio Acocella and Ursula Rabar for having encouraged us submit this Research Topic and for all their support throughout.

Bürgmann, R., and Chadwell, D. (2014). Seafloor Geodesy. Annu. Rev. Earth Planet. Sci. 42, 509-534. doi:10.1146/annurev-earth-060313-054953

Chadwick, W. W., Nooner, S. L., Butterfield, D. A., and Lilley, M. D. (2012). Seafloor Deformation and Forecasts of the April 2011 Eruption at Axial Seamount. Nat. Geosci 5, 474-477. doi:10.1038/ngeo1464

Davis, E. E., Villinger, H., and Sun, T. (2015). Slow and Delayed Deformation and Uplift of the Outermost Subduction Prism Following ETS and Seismogenic Slip Events beneath Nicoya Peninsula, Costa Rica. Earth Planet. Sci. Lett. 410, 117-127. doi:10.1016/j.epsl.2014.11.015

Fujiwara, T., Kodaira, S., No, T., Kaiho, Y., Takahashi, N., and Kaneda, Y. (2011). The 2011 Tohoku-Oki Earthquake: Displacement Reaching the Trench axis. Science 334 (6060), 1240. doi:10.1126/science.1211554 
Gagnon, K., Chadwell, C. D., and Norabuena, E. (2005). Measuring the Onset of Locking in the Peru-Chile Trench with GPS and Acoustic Measurements. Nature 434, 205-208. doi:10.1038/nature03412

Hino, R., Inazu, D., Ohta, Y., Ito, Y., Suzuki, S., Iinuma, T., et al. (2014). Was the 2011 Tohoku-Oki Earthquake Preceded by Aseismic Preslip? Examination of Seafloor Vertical Deformation Data Near the Epicenter. Mar. Geophys. Res. 35, 181-190. doi:10.1007/s11001-013-9208-2

Hirose, H., Asano, Y., Obara, K., Kimura, T., Matsuzawa, T., Tanaka, S., et al. (2010). Slow Earthquakes Linked along Dip in the Nankai Subduction Zone: Fig. 1. Science 330, 1502. doi:10.1126/science.1197102pmid:2114838410.1126/ science. 1197102

Iinuma, T., Hino, R., Kido, M., Inazu, D., Osada, Y., Ito, Y., et al. (2012). Coseismic Slip Distribution of the 2011 off the Pacific Coast of Tohoku Earthquake (M9.0) Refined by Means of Seafloor Geodetic Data. J. Geophys. Res. 117, a-n. doi:10.1029/2012JB009186

Iinuma, T., Hino, R., Uchida, N., Nakamura, W., Kido, M., Osada, Y., et al. (2016). Seafloor Observations Indicate Spatial Separation of Coseismic and Postseismic Slips in the 2011 Tohoku Earthquake. Nat. Commun. 7, 13506. doi:10.1038/ ncomms 13506

Inazu, D., Hino, R., and Fujimoto, H. (2012). A Global Barotropic Ocean Model Driven by Synoptic Atmospheric Disturbances for Detecting Seafloor Vertical Displacements from In Situ Ocean Bottom Pressure Measurements. Mar. Geophys. Res. 33, 127-148. doi:10.1007/s11001-012-9151-7

Ioki, K., and Tanioka, Y. (2016). Re-estimated Fault Model of the 17th century Great Earthquake off Hokkaido Using Tsunami deposit Data. Earth Planet. Sci. Lett. 433, 133-138. doi:10.1016/j.epsl.2015.10.009

Ito, Y., Hino, R., Kido, M., Fujimoto, H., Osada, Y., Inazu, D., et al. (2013). Episodic Slow Slip Events in the Japan Subduction Zone before the 2011 Tohoku-Oki Earthquake. Tectonophysics 600, 14-26. doi:10.1016/ j.tecto.2012.08.022

Kajikawa, H., and Kobata, T. (2019). Evaluation and Correction for Long-Term Drift of Hydraulic Pressure Gauges Monitoring Stable and Constant Pressures. Measurement 134, 33-39. doi:10.1016/j.measurement.2018.10.051

Kido, M., Osada, Y., Fujimoto, H., Hino, R., and Ito, Y. (2011). Trench-normal Variation in Observed Seafloor Displacements Associated with the 2011 Tohoku-Oki Earthquake. Geophys. Res. Lett. 38, a-n. doi:10.1029/ 2011GL050057

Polster, A., Fabian, M., and Villinger, H. (2009). Effective Resolution and Drift of Paroscientific Pressure Sensors Derived from Long-Term Seafloor Measurements. Geochem. Geophys. Geosyst. 10, a-n. doi:10.1029/ 2009GC002532
Sato, M., Ishikawa, T., Ujihara, N., Yoshida, S., Fujita, M., Mochizuki, M., et al. (2011). Displacement above the Hypocenter of the 2011 Tohoku-Oki Earthquake. Science 332, 1395. doi:10.1126/science.1207401

Sato, T., Hasegawa, S., Kono, A., Shiobara, H., Yagi, T., Yamada, T., et al. (2017). Detection of Vertical Motion during a Slow-Slip Event off the Boso Peninsula, Japan, by Ocean Bottom Pressure Gauges. Geophys. Res. Lett. 44, 2710-2715. doi:10.1002/2017GL072838

Tadokoro, K., Ando, M., Ikuta, R., Okuda, T., Besana, G. M., Sugimoto, S., et al. (2006). Observation of Coseismic Seafloor Crustal Deformation Due toM7 Class Offshore Earthquakes. Geophys. Res. Lett. 33, L23306. doi:10.1029/ 2006GL026742

Tomita, F., Kido, M., Ohta, Y., Iinuma, T., and Hino, R. (2017). Along-trench Variation in Seafloor Displacements after the 2011 Tohoku Earthquake. Sci. Adv. 3, e1700113. doi:10.1126/sciadv.1700113

Wallace, L. M., Webb, S. C., Ito, Y., Mochizuki, K., Hino, R., Henrys, S., et al. (2016). Slow Slip Near the Trench at the Hikurangi Subduction Zone, New Zealand. Science 352, 701-704. doi:10.1126/science.aaf2349

Warren-Smith, E., Fry, B., Wallace, L., Chon, E., Henrys, S., Sheehan, A., et al. (2019). Episodic Stress and Fluid Pressure Cycling in Subducting Oceanic Crust during Slow Slip. Nat. Geosci. 12, 475-481. doi:10.1038/s41561-019-0367-x

Yokota, Y., and Ishikawa, T. (2020). Shallow Slow Slip Events along the Nankai Trough Detected by GNSS-A. Sci. Adv. 6, eaay5786. doi:10.1126/ sciadv.aay5786

Conflict of Interest: The authors declare that the research was conducted in the absence of any commercial or financial relationships that could be construed as a potential conflict of interest.

Publisher's Note: All claims expressed in this article are solely those of the authors and do not necessarily represent those of their affiliated organizations, or those of the publisher, the editors and the reviewers. Any product that may be evaluated in this article, or claim that may be made by its manufacturer, is not guaranteed or endorsed by the publisher.

Copyright (c) 2021 Hino, Tadokoro and Wallace. This is an open-access article distributed under the terms of the Creative Commons Attribution License (CC BY). The use, distribution or reproduction in other forums is permitted, provided the original author(s) and the copyright owner(s) are credited and that the original publication in this journal is cited, in accordance with accepted academic practice. No use, distribution or reproduction is permitted which does not comply with these terms. 